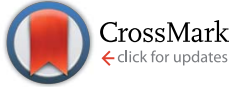

Cite this: J. Mater. Chem. A, 2015, 3, 17190

Received 28th April 2015 Accepted 16th July 2015 DOI: $10.1039 / \mathrm{c} 5 \mathrm{ta0} 120 \mathrm{f}$ www.rsc.org/MaterialsA

\section{Heat treatment of $\mathrm{ZnO}$ nanoparticles: new methods to achieve high-purity nanoparticles for high- voltage applications $\uparrow$}

\author{
A. M. Pourrahimi, ${ }^{a}$ D. Liu, ${ }^{a}$ V. Ström, ${ }^{\text {b M. S. Hedenqvist, }}{ }^{\text {a R. T. Olsson }}{ }^{a}$ \\ and U. W. Gedde*a
}

Novel methods based on orienting and coating of $\mathrm{ZnO}$ nanoparticles were studied in order to obtain uniform, nano-sized and ultra-pure $\mathrm{ZnO}$ grains/particles after heat treatment. A $1 \mathrm{~nm}$ zinc-hydroxy-salt complex layer on the nanoparticle surfaces was revealed by thermogravimetry and infrared spectroscopy. This 'phase' gradually decomposed into $\mathrm{ZnO}$ during the heat treatment while sintering occurred above $600{ }^{\circ} \mathrm{C}$, as revealed by scanning- and transmission-electron microscopy. The c-axis alignment of the nanoparticles provided smaller pores than those associated with non-oriented nanoparticles, presenting the means to obtain high-density ceramics. The orientation resulted in a smaller grain size after heat treatment than that of the nonaligned nanoparticles. Another method that involved three steps - silane coating, heat treatment and silica layer etching - was used to remove the ionic species from the nanoparticle surface while preserving its hydroxylated surface. These ultra-pure nanoparticles are expected to be key components in the development of HVDC insulation polyethylene nanocomposites.

\section{Introduction}

Renewable electric power generation is a rapidly expanding field, and there is a need to increase the long-distance transmission capacity with lower energy losses. The most feasible solution is underground and submarine high-voltage direct current (HVDC) cables with a maximum anticipated voltage of 1 MV by $2030 .{ }^{1}$ Extruded HVDC cables insulated with crosslinked polyethylene are commercially available for use up to $525 \mathrm{kV}$. $^{2}$ One strategy to enhance the insulating performance of polyethylene is by the incorporation of dispersed metal oxide (e.g. $\mathrm{ZnO}$ ) nanoparticles at very low concentrations. The nanoparticles adsorb ionic/polar species and suppress space charge accumulation in the insulating polymer matrix and thus reduce the conductivity in a high electric field. ${ }^{3-5}$ The challenge in the development of nanocomposites with ultra-low electrical conductivity is to find highly pure nanoparticles without conducting counter-ions on the particle surfaces, but, it is essential that nanoparticles are functionalized with hydroxide groups in order to allow further coating chemistry to be applied. High-

${ }^{a}$ KTH Royal Institute of Technology, School of Chemical Science and Engineering, Fibre and Polymer Technology, SE-100 44 Stockholm, Sweden. E-mail: gedde@kth.se; Fax: +468 208856; Tel: +468 7907640

${ }^{b}$ KTH Royal Institute of Technology, School of Industrial Engineering and Management, Material Science and Engineering, SE-100 44 Stockholm, Sweden

$\uparrow$ Electronic supplementary information (ESI) available. See DOI: $10.1039 / \mathrm{c} 5 \mathrm{ta} 03120 \mathrm{f}$ purity $\mathrm{ZnO}$ is essential not only for electrical insulations but also for varistor ceramics in electronic applications.

Different methods have been used to synthesize $\mathrm{ZnO}$ nanoparticles among which water-based precipitation at low temperatures is versatile, inexpensive and gives a high yield, ${ }^{6}$ and the surfaces of the nanoparticles prepared by this method have a high concentration of zinc hydroxide. ${ }^{6-10}$ The hydroxide groups are stabilized by the anions remaining from the zinc salt precursors which form quasi-crystalline zinc hydroxy salt (ZHS) $)^{11-14}$ with a composition depending on the zinc salt precursor anion. It has been suggested that the ZHS species with acetate anions create an amphiphilic capping layer around primary $\mathrm{ZnO}$ nanoparticles, and that they provide steric repulsion and colloidal stability among the particles during and after the aqueous precipitation. ${ }^{6,15,16}$ In contrast, nitrate counter-ions could not form a capping layer, the result being extensive selfassembly of the primary nanoparticles along the $c$-axis with submicron flower-shaped morphologies. ${ }^{6}$ The ZHS phase adsorbs impurities and forms hard aggregates of the nanoparticles in polymer nanocomposites. ${ }^{7}$ The ZHS decomposes due to the release of water and ionic species into pure $\mathrm{ZnO}$ during hightemperature annealing. ${ }^{\mathbf{1 1 , 1 3}}$

Heat treatment is thus efficient in transforming the nanoparticles with a surface ZHS phase into pure $\mathrm{ZnO}$, but the disadvantage is the accompanying undesirable nanoparticle sintering leading to larger particles/grains. ${ }^{17}$ A higher breakdown voltage of nanocomposites with ultra-low electrical conductivity was obtained by decreasing the particle size from 
$\mu \mathrm{m}$ to $\mathrm{nm} .{ }^{18}$ With regard to varistor applications, electrical characteristics such as the resistivity and dielectric properties of $\mathrm{ZnO}$ ceramics can be tuned by controlling the sintering process. ${ }^{19-29}$ The grain boundaries in the varistors provide a high charge barrier compared to that of the conductive $\mathrm{ZnO}$ bulk grains, and hence the breakdown voltage depends on the number of grain boundaries per unit volume. ${ }^{28,29}$ As the grain size decreases, the number of grain boundaries increases and this leads to an increase in breakdown voltage. ${ }^{30}$ Meng et al. ${ }^{27}$ obtained small-grain ultra-dense $\mathrm{ZnO}$ ceramics by a specific heat treatment with a favourable electrical performance with high breakdown strength, excellent nonlinear coefficient and low leakage current.

Different methods have been used to obtain nano-sized ZnO particles/grains after the heat treatment: sintering under different atmospheres, ${ }^{31-33}$ two-step sintering, ${ }^{26,30,34-36}$ microwave sintering, ${ }^{37}$ spark plasma sintering, ${ }^{38}$ addition of dopants, ${ }^{28,39,40}$ silica coating ${ }^{17,27}$ and sintering using oriented particles. ${ }^{29}$ Spark plasma sintering yields dense and fine-grained ceramics with a rapid sintering rate, but the method is not useful for industrial applications. ${ }^{36} \mathrm{~A}$ two-step-sintering process was developed with the purpose of obtaining large quantities of nano-sized grains. During the first step, the relative density is increased by treatment at temperatures above $900{ }^{\circ} \mathrm{C}$ by the destabilisation of pores. $^{35}$ The second step is carried out at temperatures below $600{ }^{\circ} \mathrm{C}$ with the purpose of minimizing the grain growth. The relatively low final density and the long sintering times required are drawbacks compared to the conventional one-step-sintering. ${ }^{\mathbf{4 1 , 4 2}}$ The silica coating of the particles retained the initial large surface area, and the hydroxy salt complex on the particle surfaces was transformed into pure oxide by the heat treatment.

This paper presents two new strategies to achieve high purity, fine and nano-sized $\mathrm{ZnO}$ particles/grains during the heat treatment above $600{ }^{\circ} \mathrm{C}$ intended for high-voltage applications. In both strategies, the zinc hydroxy salt phase as a surface defect was transformed to pure $\mathrm{ZnO}$. One strategy was based on silane coating of $\mathrm{ZnO}$ nanoparticles, heat treatment and finally removal of the silica layer. The processed particles had a zinc hydroxide surface without the presence of associated ionic species while preserving their nano-sizes. Another strategy was to increase the density of $\mathrm{ZnO}$ ceramics by orienting the nanoparticles and reducing the inter-particle pore size. A positive effect of nanoparticle orientation is the possible minimization of grain growth accompanying the heat treatment. It is shown that a single-step-sintering process can yield uniform, nanosized and ultra-pure $\mathrm{ZnO}$ grains.

\section{Experimental}

\subsection{Materials}

Zinc nitrate hexahydrate $\left(\mathrm{Zn}\left(\mathrm{NO}_{3}\right)_{2} \cdot 6 \mathrm{H}_{2} \mathrm{O}\right.$, $\geq 98$ wt $\%$, SigmaAldrich), zinc acetate dihydrate $\left(\mathrm{Zn}\left(\mathrm{CH}_{3} \mathrm{COO}\right)_{2} \cdot 2 \mathrm{H}_{2} \mathrm{O}, \geq 99 \mathrm{wt} \%\right.$, Sigma-Aldrich), sodium hydroxide ( $\geq 98 \mathrm{wt} \%$, Sigma-Aldrich), octadecyl trimethoxy silane (OTMS, $\geq 90 \mathrm{wt} \%$, Sigma-Aldrich), ammonia hydroxide (25 wt\%, Sigma-Aldrich), 2-propanol ( $\geq 99.5 \mathrm{wt} \%$, VWR), ethanol ( $\geq 96 \mathrm{wt} \%$, VWR) and potassium bromide (KBr, $\geq 98 \mathrm{wt} \%$, FTIR grade, Sigma-Aldrich) were used as received. High resistivity Milli-Q water $\left(18.2 \mathrm{M} \Omega \mathrm{cm}\right.$ at $\left.25^{\circ} \mathrm{C}\right)$ was used in all the aqueous reactions.

\subsection{Synthesis of $\mathrm{ZnO}$ nanoparticles}

2.2.1. Comparison of zinc salt precursor anions. $\mathrm{ZnO}$ nanoparticles were prepared by an aqueous precipitation method described by Pourrahimi et al. ${ }^{6}$ The reaction conditions were identical and only the zinc salt precursor was altered. 500 $\mathrm{mL}$ of $0.2 \mathrm{M}$ zinc salt precursor aqueous solution was prepared and vigorously stirred for $15 \mathrm{~min}$ in a $4000 \mathrm{~mL}$ glass reactor maintained at $60 \pm 0.5{ }^{\circ} \mathrm{C}$ under air. $500 \mathrm{~mL}$ of $0.5 \mathrm{M} \mathrm{NaOH}$ aqueous solution heated separately to $60{ }^{\circ} \mathrm{C}$ was added to the zinc salt precursor solution within a $3 \mathrm{~s}$ time period. The reaction proceeded under vigorous mechanical stirring at $60{ }^{\circ} \mathrm{C}$, and was allowed to react for $1 \mathrm{~h}$. After synthesis, the particle suspensions were transferred into $500 \mathrm{~mL}$ plastic centrifuge bottles and the reaction medium was replaced thrice with the same volume of MilliQ water after each centrifugation. The suspension was exposed to ultrasonication as an intermediate treatment before centrifugation and water replacement. The ultrasonication treatment was carried out for $15 \mathrm{~min}$ at $23{ }^{\circ} \mathrm{C}$ (Bandelin Sonorex RK $100 \mathrm{H}$, volume $=3 \mathrm{~L}$, ultrasonic peak output $=320 \mathrm{~W}$, and frequency $=35 \mathrm{kHz}$ ). After final centrifugation, the particles were dried at $80{ }^{\circ} \mathrm{C}$ and normal pressure, ground to a fine powder with a pestle and mortar and finally dried at $60{ }^{\circ} \mathrm{C}$ and $20 \mathrm{kPa}$ for $2 \mathrm{~h}$. The prepared particles are designated as $\mathrm{ZN}-8 \mathrm{~g}$ and $\mathrm{ZA}-8 \mathrm{~g}$, indicating the zinc salt $(\mathrm{ZN}=$ zinc nitrate, $\mathrm{ZA}=$ zinc acetate) and the yield of the reaction $(8 \mathrm{~g})$.

2.2.2. Study of zinc hydroxy salt (ZHS) transformation. Different concentrations of zinc acetate solution (0.05, 0.1, 0.15 and $0.25 \mathrm{M}$; volume $=500 \mathrm{~mL}$ ) were used to prepare zinc oxide nanoparticles in various amounts, the concentration of the $\mathrm{NaOH}$ solution being 2.5 times the concentration of the zinc precursor solution. The amounts of the precipitated particles were 2, 4, 6 and $10 \mathrm{~g} \mathrm{~L}^{-1}$, designated as: ZA-2g, ZA-4g, ZA-6g and ZA-10g, respectively. ${ }^{6}$ All the materials were prepared under the conditions described in Section 2.2.1.

2.2.3. OTMS coating of $\mathrm{ZnO}$ nanoparticles. $0.6 \mathrm{~g} \mathrm{ZnO}$ nanoparticles (ZA-8g) were dispersed in a solution of $40.8 \mathrm{~mL}$ Milli-Q water and $188.4 \mathrm{~mL}$ 2-propanol. Ammonia hydroxide $(1.28 \mathrm{~mL})$ was added to the $\mathrm{ZnO}$ suspension. The suspension was stirred for $15 \mathrm{~min}$, and $0.41 \mathrm{~mL}$ octadecyl trimethoxy silane (OTMS) was then added to the suspension and allowed to react for $3 \mathrm{~h}$ at room temperature. The coated particles were centrifuged and washed thrice in ethanol to remove excess OTMS and the particles were finally dried at $80{ }^{\circ} \mathrm{C}$ overnight.

\subsection{Heat treatment of zinc oxide particles}

The ZnO particles were heat-treated from $23{ }^{\circ} \mathrm{C}$ to $600{ }^{\circ} \mathrm{C}$ with a heating rate of $10^{\circ} \mathrm{C} \mathrm{min}{ }^{-1}$ and held at $600^{\circ} \mathrm{C}$ for $1 \mathrm{~h}$ in a muffle furnace (ML Furnaces) with ambient air. The heat-treated particles were designated as $\mathrm{ZA}-8 \mathrm{~g} \mathrm{~T}$ and $\mathrm{ZN}-8 \mathrm{~g} \mathrm{~T}$. For the grain growth study, pristine and OTMS-coated ZA-8g were heattreated in a Mettler Toledo TG/DSC 1 at different temperatures $\left(600,800\right.$ and $\left.1000{ }^{\circ} \mathrm{C}\right)$ and for different periods of time (10, 
$30,60,120$ and $240 \mathrm{~min}$ ) in dry nitrogen with a flow rate of $50 \mathrm{~mL} \mathrm{~min}^{-1}$.

\subsection{Alkaline etching}

After heat treatment, the $0.4 \mathrm{~g}$ OTMS-coated ZA-8g nanoparticles were dispersed in $50 \mathrm{~mL}$ of $1 \mathrm{M} \mathrm{NaOH}$ aqueous solution under ultrasonication for $30 \mathrm{~min}$ in order to remove the silica shell. The applied energy per volume (weight) of the nanoparticle material in the suspension was estimated to be $c a$. $4.8 \mathrm{~kJ}$ per $50 \mathrm{~mL}$ of particles $(0.4 \mathrm{~g})$. The etched $\mathrm{ZnO}$ nanoparticles were purified thrice in ultrasonicated Milli-Q water.

\subsection{Particle characterisation}

A field emission scanning electron microscope (SEM; Hitachi S4800) and a transmission electron microscope (TEM; Hitachi HT7700) were used to assess the habit and size distributions of the ZnO nanoparticles. For SEM: powder samples were coated with a thin conductive layer of Pt/Pd (60/40) for $20 \mathrm{~s}$ of sputtering using a current of $80 \mathrm{~mA}$ in a Cressington $208 \mathrm{HR}$. The samples were examined in the microscope with an acceleration voltage of $5 \mathrm{kV}$ and a current of $10 \mu \mathrm{A}$. The size distribution of the nanoparticles was obtained by manually measuring 600 particles using ImageJ (National Institute of Health, Maryland, USA). For TEM: the particles were deposited on 400 mesh copper grids from a suspension of pure ethanol containing a particle concentration of $0.45 \pm 0.05 \mathrm{~g} \mathrm{~L}^{-1}$. The samples were dried and examined in the microscope operating at an acceleration voltage of $100 \mathrm{kV}$.

The Brunauer-Emmett-Teller (BET) method based on nitrogen adsorption/desorption with a Micromeritics ASAP 2000 at $77 \mathrm{~K}$ was used to determine the specific surface area and pore size distribution.

X-ray diffractograms of the powder samples were recorded at room temperature using a PANalytical X'pert Pro MPD diffractometer with a $\mathrm{Cu}-\mathrm{K} \alpha$ source (wavelength $=1.54178 \AA$ ) using a $2 \theta$ step size of $0.017^{\circ}$. The crystal size was obtained from the Scherrer equation:

$$
D=\frac{k \lambda}{\beta \cos \theta}
$$

where $D$ is the crystal size in $\mathrm{nm}, k$ is a shape factor equal to $0.89, \lambda$ is the wavelength $(0.154178 \mathrm{~nm}), \theta$ is the Bragg angle and $\beta$ is the peak width at half-maximum (FWHM) in radians.

Thermogravimetry (TG) was carried out in a Mettler Toledo TG/DSC 1. Powder samples weighing $5 \pm 1 \mathrm{mg}$ were placed in 70 $\mu \mathrm{L}$ alumina crucibles and heated from 30 to $800{ }^{\circ} \mathrm{C}$ at a rate of $10{ }^{\circ} \mathrm{C} \mathrm{min}^{-1}$ in dry nitrogen with a flow rate of $50 \mathrm{~mL} \mathrm{~min}{ }^{-1}$.

Infrared spectra of the nanoparticle samples before and after heat treatment were recorded with a Perkin-Elmer Spectrum 2000 FTIR spectrometer and analysed with Perkin-Elmer Spectrum software (Norwalk, CT, USA). The samples were prepared by mixing $3 \mathrm{mg}$ of particles and $300 \mathrm{mg}$ of ground $\mathrm{KBr}$ and pressing the mixture under a load of $100 \mathrm{kN}$ for $1 \mathrm{~min}$ in a die to form a pellet. The wavenumber range used was $450 \mathrm{~cm}^{-1}$ to $4000 \mathrm{~cm}^{-1}$ with a spectral resolution of $4 \mathrm{~cm}^{-1}$. Each spectrum was based on 32 scans.
Photoluminescence (PL) emission measurements were performed at $23{ }^{\circ} \mathrm{C}$ in a Perkin-Elmer LS55 instrument equipped with a Xe lamp. An aqueous particle suspension with a particle concentration of $2.67 \mathrm{~g} \mathrm{~L}^{-1}$ was placed in a quartz cuvette with an inner cross-section of $10 \times 10 \mathrm{~mm}^{2}$. The excitation wavelength was $290 \mathrm{~nm}$, and both the excitation and emission slits had a width of $5 \mathrm{~nm}$.

X-ray photoelectron spectroscopy (XPS) spectra were collected with a Kratos Axis Ultra DLD electron spectrometer using a monochromatic $\mathrm{Al} \mathrm{K}_{\alpha}$ source operating at $150 \mathrm{~W}$. An analyser pass energy of $160 \mathrm{eV}$ for acquiring wide spectra and a pass energy of $20 \mathrm{eV}$ for individual photoelectron lines were used. The surface potential was stabilized by using the spectrometer charge neutralization system. The binding energy (BE) scale was referenced to the $\mathrm{C} 1 \mathrm{~s}$ line of aliphatic carbon, set at $285.0 \mathrm{eV}$. The spectra were processed with the Kratos software. Powder samples for the analysis were pressed into a pellet directly on a sample holder using a Ni spatula.

\section{Results and discussion}

\subsection{Morphology of $\mathrm{ZnO}$ particles}

Fig. 1a and b show transmission electron micrographs of the $\mathrm{ZnO}$ particles synthesized from zinc acetate and zinc nitrate precursors, respectively. The zinc acetate precursor yielded separate and randomly oriented nanoparticles with an average size of $c a$. $25 \mathrm{~nm}$, whereas zinc nitrate yielded submicron flowershaped particles with a symmetrical habit. These submicron particles consisted of $c$-axis oriented primary nanoparticles along each petal (spike) director, as shown by black arrows (Fig. 1b). This important finding was confirmed by electron diffraction and high resolution TEM data presented elsewhere ${ }^{6}$ (see also ESI, Fig. S1†). Oliveira et al. ${ }^{43}$ observed the orientation of nanoparticles inside flower-shaped particles in a kinetic study of the reaction between zinc nitrate and sodium hydroxide. It was reported in another paper that only a few nanoparticles deviated from perfect alignment as a result of lattice imperfection, and improper stacking in contacting areas among the primary nanoparticles ${ }^{\mathbf{4 4}}$ inside the flower-shaped particles.

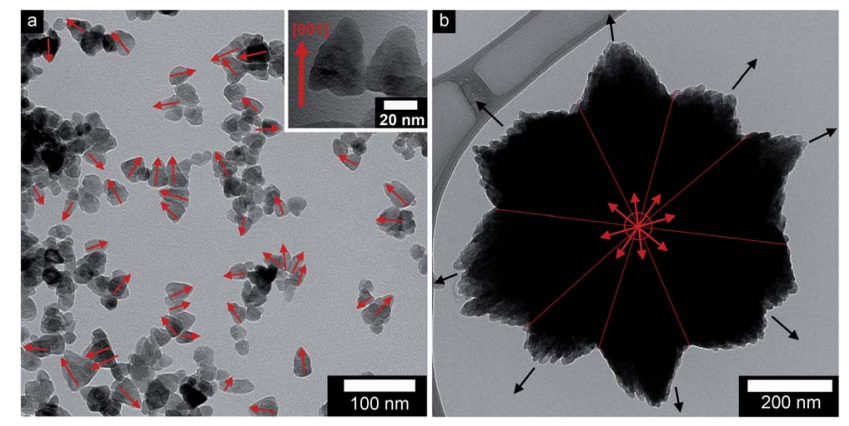

Fig. 1 Transmission electron micrographs of $\mathrm{ZnO}$ nanoparticles: (a) non-oriented (ZA-8g) and (b) oriented (ZN-8g) (red and black arrows show the $c$-axis and director). 

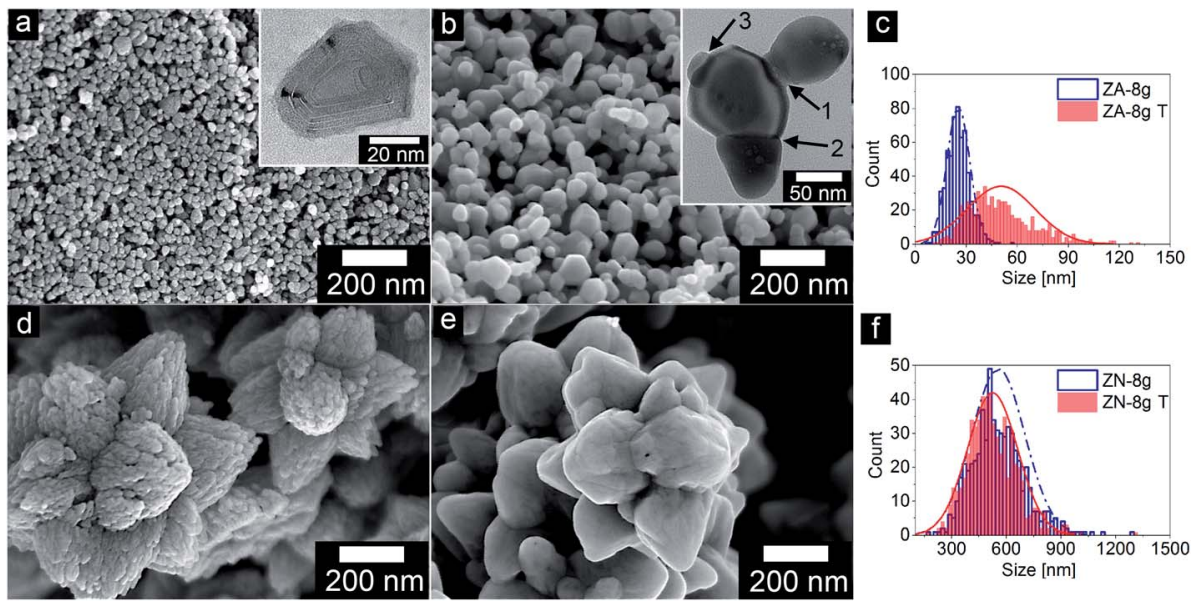

Fig. 2 Scanning electron micrographs of $\mathrm{ZnO}$ particles before and after heat treatment at $600^{\circ} \mathrm{C}$ in air (a) $\mathrm{ZA}-8 \mathrm{~g}$, the inset shows the terrace-like surface of a $\mathrm{ZnO}$ nanoparticle from top view; (b) ZA- $8 \mathrm{~g} \mathrm{~T}$, arrows marked 1, 2 and 3 show the sintering steps as neck formation, grain boundary formation and Ostwald ripening, respectively; (d) ZN-8g; (e) ZN-8g T; (c) and (f) particle size distribution.

Fig. 2 presents scanning electron micrographs of nonoriented and aligned $\mathrm{ZnO}$ nanoparticles, before and after heat treatment at $600{ }^{\circ} \mathrm{C}$, together with the particle size distributions. The heat treatment smoothed the niched surface of both nano and submicron particles and the nanoparticles merged into larger grains. The nanoparticles doubled in size while the submicron particles decreased from $c a .550$ to $520 \mathrm{~nm}$ during the heat treatment (Table 1). Mouzon et al. ${ }^{45}$ modelled the transient structure during sintering. According to their model, necks and grain boundaries between the primary particles were formed and the sharp edges of the nanoparticles curved due to a process referred to as the spheroidization process. ${ }^{45} \mathrm{Gu}$ et al. $^{\mathbf{4 6}}$ removed the terrace-like surface (shown in the inset of Fig. 2a) of the $\mathrm{ZnO}$ particles by heat treatment at $1100{ }^{\circ} \mathrm{C}$ in air and obtained nanoparticles with atomically smooth $\mathrm{Zn}$ - and $\mathrm{O}$ terminated surfaces. After the grain boundary had formed, the smaller particles were consumed by the larger particles by an Ostwald ripening process (sublimation and recrystallization on larger particles). ${ }^{33,47}$ These steps are shown in Fig. $2 b$ (the inset micrograph). The fact that the oriented nanoparticle aggregates decreased in size by $6 \%$ on heat treatment suggested that the sintering of the oriented nanoparticles increased the density by $20 \%$ (assuming that the bulk density is proportional to the reciprocal of the oriented nanoparticle aggregate volume) by the

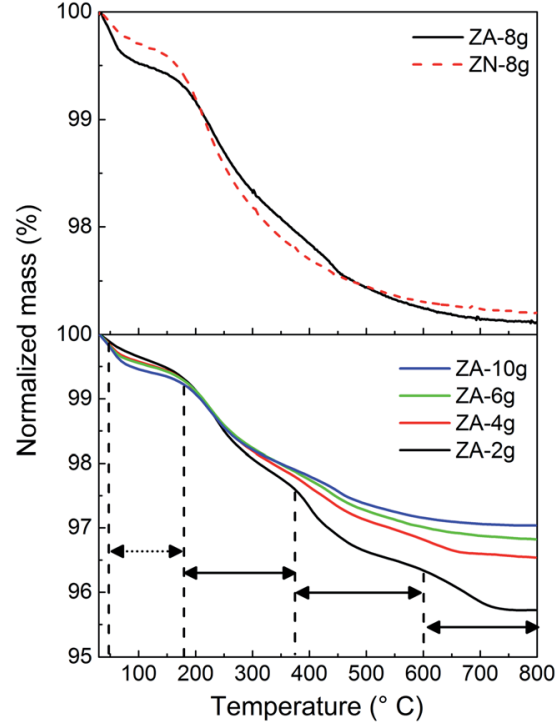

Fig. 3 Normalized mass plotted as a function of temperature as revealed by TG for the different $\mathrm{ZnO}$ particles prepared. Dashed and solid arrows indicate the low and high temperature ranges.

Table 1 Sintering characteristics of $\mathrm{ZnO}$ particles before and after heat treatment at $600{ }^{\circ} \mathrm{C}$ in air

\begin{tabular}{|c|c|c|c|c|c|c|}
\hline Sample & Metal salt precursor & $\begin{array}{l}\text { SEM particle } \\
\text { size }(\mathrm{nm})\end{array}$ & $\begin{array}{l}\text { BET surface } \\
\text { area }\left(\mathrm{m}^{2} \mathrm{~g}^{-1}\right)\end{array}$ & $\begin{array}{l}\text { Crystal size } \\
(\mathrm{nm})\end{array}$ & $\begin{array}{l}\text { Crystal size ratio } \\
\left(D_{c \text {-axis }} / D_{a \text {-axis }}\right)^{b}\end{array}$ & $\begin{array}{l}\text { Volume of unit-cell } \\
\left(\AA^{3}\right)\end{array}$ \\
\hline $\mathrm{ZA}-8 \mathrm{~g}$ & $\mathrm{Zn}\left(\mathrm{O}_{2} \mathrm{CCH}_{3}\right)_{2} \cdot 2 \mathrm{H}_{2} \mathrm{O}$ & $25 \pm 6$ & 33.6 & 22 & 1.19 & 47.9 \\
\hline $\mathrm{ZN}-8 \mathrm{~g}$ & $\mathrm{Zn}\left(\mathrm{NO}_{3}\right)_{2} \cdot 6 \mathrm{H}_{2} \mathrm{O}$ & $555 \pm 146$ & 12.6 & 22 & 1.47 & 47.9 \\
\hline $\mathrm{ZN}-8 \mathrm{~g} \mathrm{~T}$ & $\mathrm{Zn}\left(\mathrm{NO}_{3}\right)_{2} \cdot 6 \mathrm{H}_{2} \mathrm{O}$ & $524 \pm 137$ & 3.8 & 25 & 1.00 & 47.8 \\
\hline
\end{tabular}



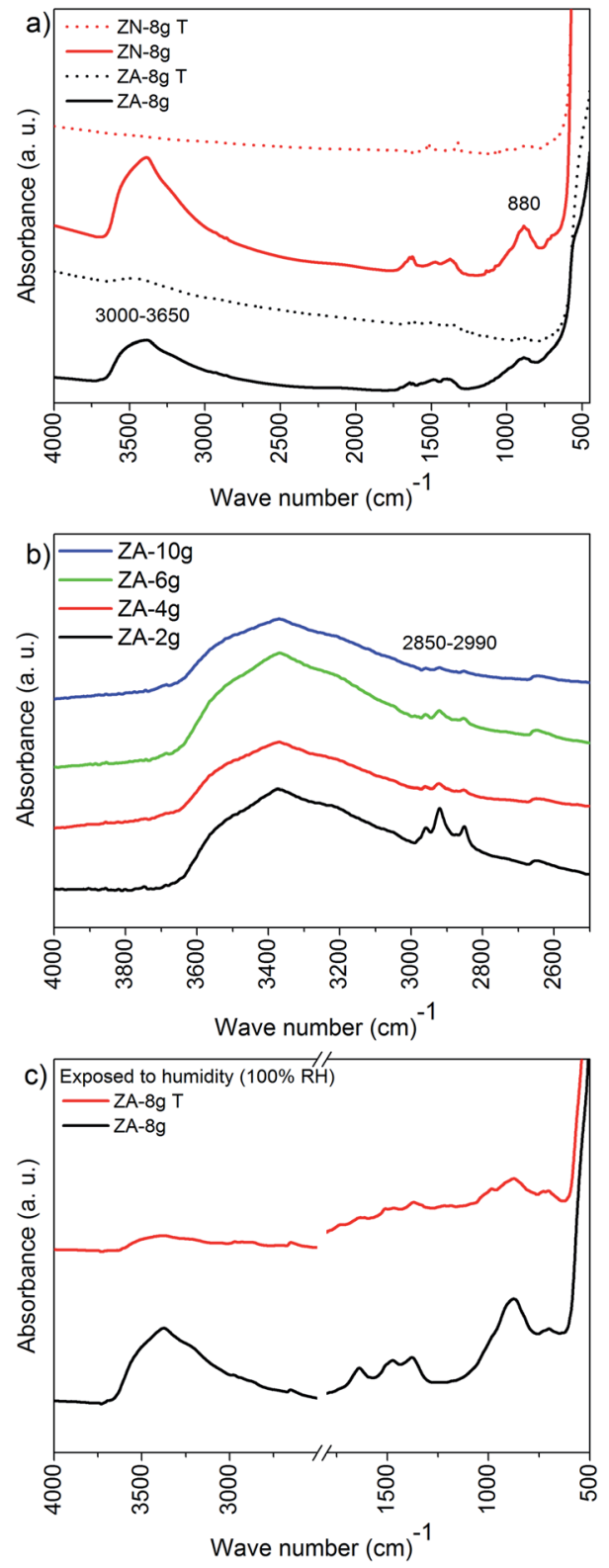

Fig. 4 IR spectra of $\mathrm{ZnO}$ particles (a) synthesized from nitrate and acetate zinc salt precursors in $8 \mathrm{~g}$ batches before (continuous curve) and after (dotted curve) heat treatment at $600^{\circ} \mathrm{C}$ in air, (b) synthesized from different concentrations of the zinc acetate precursor, and (c) heat-treated nanoparticles after exposure to humid air.

elimination of inter-particle pores. These pores are further discussed in Section 3.3.

\subsection{Thermal decomposition of zinc hydroxy salt (ZHS) into ZnO}

Fig. 3 (upper diagram) shows the normalized mass plotted as a function of temperature for non-oriented and oriented nanoparticle systems. The total mass losses of less than $3 \%$ in the thermograms were divided into a low $\left(30-185^{\circ} \mathrm{C}\right)$ and a high temperature $\left(185-800{ }^{\circ} \mathrm{C}\right)$ region. The former was assigned to the removal of loosely bound water on the nanoparticle surface, and the latter was attributed to the decomposition of ZHS into ZnO. ${ }^{11}$ The greater mass loss of the non-oriented nanoparticle system (ZA-8g) in the low temperature region was due to the larger surface area $\left(33.6 \mathrm{~m}^{2} \mathrm{~g}^{-1}\right)$ accessible for water sorption in this sample compared to the sample based on the densely packed oriented nanoparticles (ZN-8g) $\left(12.6 \mathrm{~m}^{2} \mathrm{~g}^{-1}\right)$ (Table 1). The mass loss in the high temperature region was $2.5 \%$ regardless of the nanoparticle orientation (Table 1), which suggests that the hydroxyl group concentration on the nanoparticles was the same in the two systems (ZA-8g and ZN-8g).

It was reported that the ZHS phase formed as an intermediate complex during $\mathrm{ZnO}$ particle precipitation. ${ }^{48,49}$ For the acetate system, the amount of ZHS composition increased with a decrease in the concentration of zinc acetate solution during the aqueous precipitation of $\mathrm{ZnO}$ particles. ${ }^{49}$ In order to clarify the decomposition of ZHS species on the surface of ZnO particles, TG was carried out on samples based on non-oriented $\mathrm{ZnO}$ nanoparticles synthesized using different concentrations of the zinc acetate precursor (Fig. 3 (lower diagram)). The mass loss curves showed four distinct regions of mass loss in the case of the ZA-samples: $20-185{ }^{\circ} \mathrm{C}$ (loosely bound water), $185-380{ }^{\circ} \mathrm{C}$, $380-600{ }^{\circ} \mathrm{C}$ and $600-800{ }^{\circ} \mathrm{C}$ (decomposition of ZHS into ZnO). Moezzi et al. ${ }^{11}$ reported that acetone, acetic acid, acetic anhydride and water evaporated in three steps at high temperatures during the thermal decomposition of ZHS into ZnO. The different products indicated that the ZHS structure was $\mathrm{Zn}_{5}(\mathrm{OH})_{8}\left(\mathrm{C}_{2} \mathrm{H}_{3} \mathrm{O}_{2}^{-}\right)_{2} \cdot 2 \mathrm{H}_{2} \mathrm{O}^{8,11}$ The proposed chemical reaction for the decomposition of ZHS into $\mathrm{ZnO}$ is:

$$
\begin{aligned}
& \mathrm{Zn}_{5}(\mathrm{OH})_{8}\left(\mathrm{C}_{2} \mathrm{H}_{3} \mathrm{O}_{2}^{-}\right)_{2} \cdot 2 \mathrm{H}_{2} \mathrm{O}(\mathrm{s}) \rightarrow 5 \mathrm{ZnO}(\mathrm{s}) \\
& +2 \mathrm{H}\left(\mathrm{C}_{2} \mathrm{H}_{3} \mathrm{O}_{2}^{-}\right)(\mathrm{g})+5 \mathrm{H}_{2} \mathrm{O}(\mathrm{g})
\end{aligned}
$$

According to the stoichiometry of this decomposition reaction, the measured high-temperature $\left(>185{ }^{\circ} \mathrm{C}\right)$ mass loss of $2.5 \%$ from $\mathrm{ZA}-8 \mathrm{~g}$ indicated that $7.3 \%$ of the $\mathrm{ZnO}$ nanoparticles were covered by ZHS. It was assumed that the ZHS phase was uniformly distributed over the exterior surface of the spherical ZnO nanoparticles. The calculated ZHS thickness on the ZnO nanoparticle surface was close to $1 \mathrm{~nm}$. The expected thickness of the ZHS layer ranges between 1 and $1.6 \mathrm{~nm}$ depending on the size of the anions and their interaction with the zinc hydroxide layer..$^{50} \mathrm{~A}$ thickness of $1 \mathrm{~nm}$ corresponds to one atomic layer of ZHS on the surface of a ZnO nanoparticle.

Fig. 4a shows the IR spectra of the non-oriented and oriented nanoparticle samples before (continuous line) and after (broken line) heat treatment in air at $600{ }^{\circ} \mathrm{C}$. The absorbance band at $450-600 \mathrm{~cm}^{-1}$ is assigned to the $\mathrm{Zn}-\mathrm{O}$ stretching and the absorbance band at $880 \mathrm{~cm}^{-1}$ originates from the stretching vibration of $\mathrm{Zn}-\mathrm{OH} .^{51}$ Two different interaction types of $\mathrm{OH}$ groups on the surface of $\mathrm{ZnO}$ particles have been reported: ${ }^{52}$ (i) the $3000-3650 \mathrm{~cm}^{-1}$ band is due to the reversible dissociative adsorption of hydrogen on both $\mathrm{O}$ and $\mathrm{Zn}$ sites; (ii) the 1610$1630 \mathrm{~cm}^{-1}$ band is due to chemisorbed water. The broad peak at ca. $1365 \mathrm{~cm}^{-1}$ corresponds to the nitrate anion vibration, and the peak at $c a .1635 \mathrm{~cm}^{-1}$ shows the $\delta$-vibration of interlayer water for the ZHS structure, ${ }^{50}$ which were found in the spectrum of $\mathrm{ZN}-8 \mathrm{~g}$. The two broad absorbance peaks at $1380-1390^{-1} \mathrm{~cm}$ 
and $1480-1510 \mathrm{~cm}^{-1}$ are assigned to the $\mathrm{C}-\mathrm{O}$ and $\mathrm{C}=\mathrm{O}$ stretching vibrations in the acetate anion, ${ }^{\mathbf{5 0 , 5 3}}$ which were present in the spectrum of ZA-8g. The intensities of the nitrate and acetate peaks around $1500 \mathrm{~cm}^{-1}$ were slightly weak due to their low concentrations; however the presence of acetate groups was confirmed by the XPS experimental results described in Section 3.4. The high concentration of acetate anions in ZA-2g, as indicated by TG (Fig. 3b), was also confirmed by IR; the three intensities assigned to $\mathrm{C}-\mathrm{H}$ stretching (2850$2990 \mathrm{~cm}^{-1}$ ) were the highest for this particular sample (Fig. 4b). The heat-treated samples showed none of the absorbance bands assigned to the ZHS structure (Fig. 4a). The IR spectrum of the heat-treated nanoparticles after exposure to humid air (100\% $\mathrm{RH}$ for $3 \mathrm{~h}$ ) showed a very small amount of either chemi- or physi-sorbed water or zinc hydroxide (Fig. 4c). This was proof that the heat-treated $\mathrm{ZnO}$ nanoparticles retained their structures even after extended exposure to moisture.

\subsection{Sintering characteristics of oriented $\mathrm{ZnO}$ nanoparticles}

Fig. 5 presents nitrogen desorption/adsorption isotherms together with the corresponding Barret-Joyner-Halenda (BJH) pore size distributions (insert graphs) of the $\mathrm{ZnO}$ particles before and after heat treatment in air at $600{ }^{\circ} \mathrm{C}$. All the samples obeyed the isotherm type III with hysteresis loops of different sizes according to the IUPAC classification. ${ }^{54}$ The samples based on non-oriented nanoparticles prior to heat treatment exhibited a small H1 hysteresis loop, suggesting nanoparticles with a uniform size. A large H3 hysteresis loop was observed in the case of the sample with oriented nanoparticles, suggesting that the pores had a slit shape. The pores in solid materials are classified as intra-particle, inter-particle and inter-aggregate based on the pore size. ${ }^{55}$ Since the nanoparticles in both systems were synthesized as mono-domain crystals, ${ }^{6}$ they did not show any intra-particle porosity. The non-oriented nanoparticles showed a small volume of inter-particle pores (2 to 4 $\mathrm{nm}$ ), and a large volume of inter-aggregation pores (5 to $50 \mathrm{~nm}$ ). The oriented nanoparticle system showed mainly inter-particle pores $(3.5 \mathrm{~nm})$ among the primary nanoparticles inside the submicron flower-shaped particles. The inter-particle pores in the oriented nanoparticle system were entirely removed by heat treatment, whereas the sample based on non-oriented nanoparticles retained its inter-particle pores (Fig. $5 \mathrm{c}$ and $\mathrm{d}$ (the inset graph)). This demonstrates the ultra-dense structure of heattreated oriented nanoparticles.

The removal of pores and the densification during heat treatment are related to the sintering stress, ${ }^{56,57}$ defined as the mechanical stress required to overcome the surface energy on grain boundaries during sintering, which is proportional to the reciprocal pore size..$^{56-58}$ The pore sizes were taken to be $3.5 \mathrm{~nm}$ in the oriented nanoparticle system and $25 \mathrm{~nm}$ in the nonoriented nanoparticle system. Consequently, the sintering stress for a sample with oriented nanoparticles ( $\mathrm{ZN}-8 \mathrm{~g})$ was $c a .7$ times larger than that for a sample with non-oriented nanoparticles (ZA-8g), causing less grain growth of the oriented nanoparticles.

Fig. 6a shows X-ray diffractograms of the $\mathrm{ZnO}$ particles before and after heat treatment at $600{ }^{\circ} \mathrm{C}$ in air. None of the samples showed any sign of a zinc hydroxy salt structure, indicating that the thickness of the ZHS layer was below the Xray detection limit e.g. $3 \mathrm{~nm}^{6}$ This is in accordance with the predicted layer thickness of $1 \mathrm{~nm}$ revealed by TG (Section 3.2). All the ZnO samples were highly crystalline with diffraction peaks corresponding to the expected lattice planes with a Miller
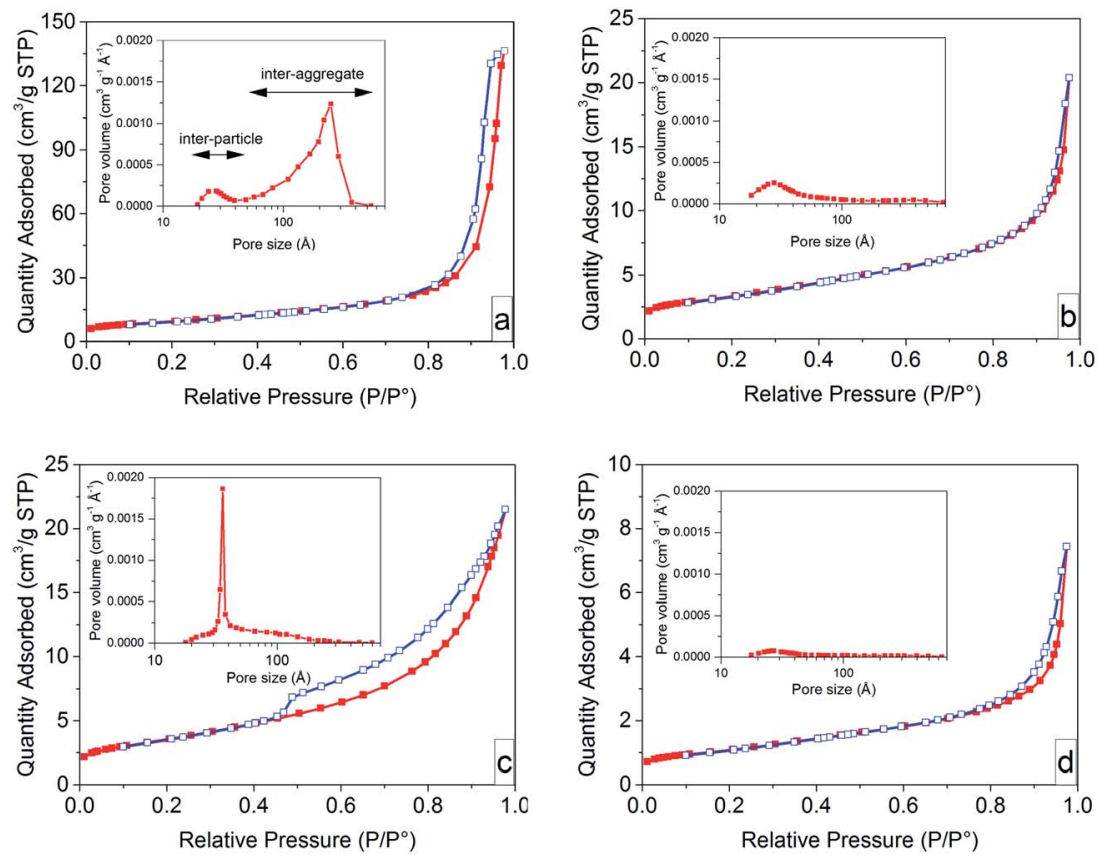

Fig. 5 Nitrogen adsorption (red filled squares) - desorption (blue open squares) isotherms of $\mathrm{ZnO}$ particles before and after heat treatment at $600{ }^{\circ} \mathrm{C}$ in air (a) ZA-8g, (b) ZA-8g T, (c) ZN-8g, and (d) ZN-8g T. Inset: the corresponding BJH (Barret-Joyner-Halenda) pore size distribution. 

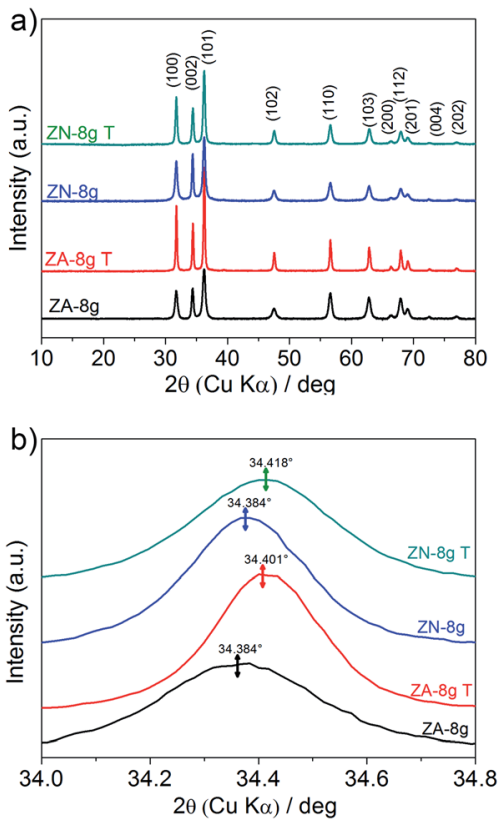

Fig. 6 (a) X-ray diffractograms of $\mathrm{ZnO}$ particles before (data obtained from ref. 6) and after heat treatment at $600{ }^{\circ} \mathrm{C}$ in air (marked $\mathrm{T}$ in the figure). (b) Close-up of the (002) diffraction peaks for the different samples.

index of $(h k l)$ in the Wurtzite crystal structure. The Wurtzite lattice parameters, e.g. the crystal interplanar distances $(d)$, were calculated from the Bragg equation $(\lambda=2 d \sin \theta)$; the lattice constants $a$ and $c$ and the crystal unit-cell volume $(V)$ were obtained from the lattice geometry equations: ${ }^{59}$

$$
\frac{1}{d^{2}}=\frac{4}{3}\left(\frac{h^{2}+h k+k^{2}}{a^{2}}\right)+\frac{l^{2}}{c^{2}}
$$

$$
V=\frac{\sqrt{3}}{2} a^{2} c
$$

Fig. $6 \mathrm{~b}$ shows a slight peak shift to higher diffraction angles, i.e. a shorter interplanar distance and a smaller unit cell volume, as a result of the heat treatment (Table 1). The shrinkage of the unit cell is in accordance with earlier published data, which was attributed to the relaxation of defects inside the crystal unit cells, e.g. zinc and oxygen vacancies. ${ }^{60,61}$ In order to gain more information about the crystal defects, photoluminescence measurements were conducted on $\mathrm{ZnO}$ samples before and after heat treatment (Fig. 7). All the samples showed a strong and broad emission band in the ultraviolet, violet and blue regions (370-500 $\mathrm{nm}$ ) together with a weak emission band in the green region (520-540 $\mathrm{nm}$ ). These emissions have been attributed to a variety of vacancy and interstitial defects on the surface and grain boundaries of the ZnO particles. ${ }^{62,63}$ The onset of the spectra was observed at longer wavelengths for the oriented nanoparticles after heat treatment. In order to clarify this shift, the spectra of oriented nanoparticles before and after heat treatment were deconvoluted into a series of relatively sharp Gaussian peaks centred at 386, 405, 417, 459, 484 and 530 $\mathrm{nm}$. It was observed that the peak at $386 \mathrm{~nm}(3.21 \mathrm{eV})$ disappeared and the intensity of the peak at $405 \mathrm{~nm}(3.06 \mathrm{eV})$ clearly decreased. The former peak was assigned to near-bandedge emission, and the latter was responsible for electron transition from the conduction band to the zinc vacancy as an acceptor level, $0.3 \mathrm{eV}$ above the valance band. ${ }^{62}$ These high energy transitions were attributed to poor crystal quality and the presence of band-edge defects ${ }^{64}$ in $\mathrm{ZnO}$ nanoparticles before heat treatment. However, the heat treatment of oriented $\mathrm{ZnO}$ nanoparticles removed the high-energy barrier of crystal lattice

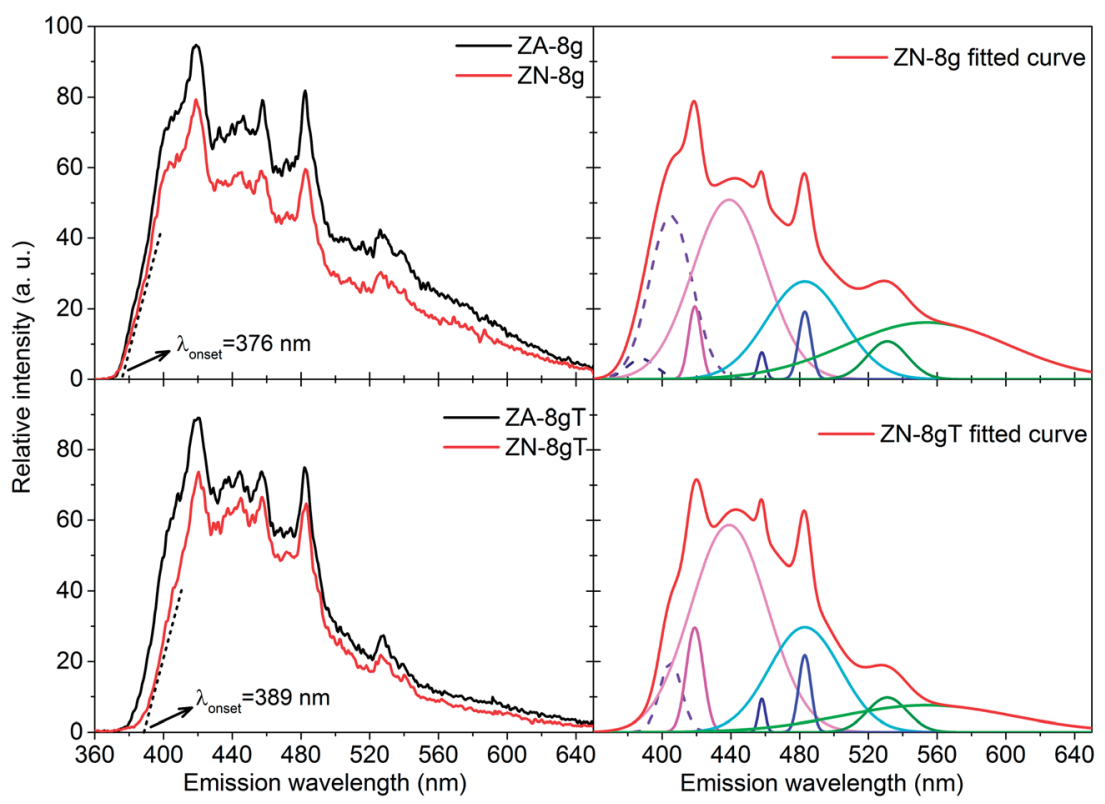

Fig. 7 Photoluminescence spectra of $\mathrm{ZnO}$ particles before (top) (data obtained from ref. 6) and (bottom) after heat treatment at $600{ }^{\circ} \mathrm{C}$ in air together with deconvoluted peaks. The excitation wavelength was $290 \mathrm{~nm}$. 
defects with reference to that of the non-oriented $\mathrm{ZnO}$ nanoparticles.

The crystal size increased by $55 \%$ and $14 \%$, respectively, for $\mathrm{ZA}-8 \mathrm{~g}$ and $\mathrm{ZN}-8 \mathrm{~g}$, indicating that there were significant crystal lattice diffusion and grain growth of the non-oriented nanoparticles compared to the oriented nanoparticles inside the flower-shaped particles (Table 1). Yang et al. ${ }^{65}$ found repulsive dipole-dipole interactions between nanoparticle surfaces inside oriented nanoparticle aggregates, which inhibited the fusion of $\mathrm{ZnO}$ crystals during synthesis. It is suggested here that this repulsive energy between oriented nanoparticles inside submicron flower-shaped particles inhibited the crystal growth during the heat treatment. The crystal aspect ratio $\left(D_{c \text {-axis }} / D_{a \text {-axis }}\right)$ showing the crystal habit ${ }^{66}$ decreased by $6 \%$ and $32 \%$ for the non-oriented and oriented nanoparticle systems, respectively, during heat treatment. The aspect ratio of the $\mathrm{ZnO}$ crystals in all the systems was close to 1 after heat treatment, which means that the heat treatment changed the crystallographic direction growth and made the crystals equiaxial. This process occurred due to the surface and volume diffusion on solitary particles or Ostwald ripening by the contribution of the adjacent particles during heat treatment (see Fig. 2b inset). Suvaci and Özer ${ }^{29}$ showed that the $\mathrm{ZnO}$ templates aligned on the $c$-axis grew anisotropically during sintering. The $\mathrm{ZnO}$ nanoparticles with a pyramidal morphology exhibit a basal polar zinc plane of (001) and nonpolar prismatic planes of (110) and (100) with both zinc and oxygen termination. ${ }^{67}$ The grain growth of the $\mathrm{ZnO}$ nanoparticles during post heat treatment was greater for nonpolar prismatic planes than for polar planes. ${ }^{33}$ Therefore, the nanoparticles aligned along the $c$-axis; the prismatic crystal planes grew faster due to the more favourable zinc and oxygen atom arrangements, ${ }^{29,68}$ resulting in lower grain growth along the $c$ direction for oriented particles. This shows that particle orientation can be used as a method to obtain dense ceramics with minimal grain growth during heat treatment. The previous sintering methods (for example in ref. 19, 36 and 42) to obtain fully-dense $\mathrm{ZnO}$ ceramics are not able to retain the grain size less than $100 \mathrm{~nm}$ under low temperature heat treatment (i.e. below $600{ }^{\circ} \mathrm{C}$ ). In contrast, we show that the orientation of $\mathrm{ZnO}$ nanoparticles could pave the way to achieve a new generation of ultra-dense $\mathrm{ZnO}$ ceramics for varistor applications with grain sizes less than $25 \mathrm{~nm}$ and a large number of grain boundaries per unit volume.

\subsection{Grain growth of coated $\mathrm{ZnO}$ nanoparticles}

Fig. 8 shows scanning electron micrographs of ZnO nanoparticles with and without OTMS coating on the nanoparticle surfaces, which were heat-treated for $1 \mathrm{~h}$ in nitrogen at different temperatures. The heat treatment was carried out in nitrogen in order to avoid the effect of oxygen from the surrounding air on the $\mathrm{ZnO}$ sintering process. The average size of the $\mathrm{ZnO}$ nanoparticles without coating was essentially unaffected by heat treatment at $600{ }^{\circ} \mathrm{C}$. More subtle changes in the particles occurred, such as rounding of the sharp edges of the nanoparticles. The grain size increased sharply with increasing heat treatment temperature above $800^{\circ} \mathrm{C}$. The OTMS coating on $\mathrm{ZnO}$ nanoparticle surfaces inhibited the grain growth, and the sintering occurred at temperatures above $1000{ }^{\circ} \mathrm{C}$. The grain growth of $\mathrm{ZnO}$ particles has been extensively investigated for more than 50 years. ${ }^{39,40,69-73}$ The kinetics of the grain growth is conveniently described by: ${ }^{73}$

$$
G^{n}=K_{0} t^{\frac{-Q}{R T}}
$$

where $G$ is the average grain size, $n$ is the kinetic grain growth exponent, $Q$ is the apparent activation energy, $R$ is the gas constant, $K_{0}$ is a constant, $t$ is time and $T$ is the absolute temperature. The average grain size in a polycrystalline ceramic material is given by: ${ }^{74}$

$$
G=1.56 L
$$

where $L$ is the average grain-boundary intercept length measured randomly on the scanning electron micrographs.

Fig. 9a shows the isothermal grain growth of the $\mathrm{ZnO}$ nanoparticles with and without coating as a function of heat treatment time. The kinetic grain growth exponent was obtained from the slope of the fitted $\operatorname{line}$ of $\log G v s . \log t$, which

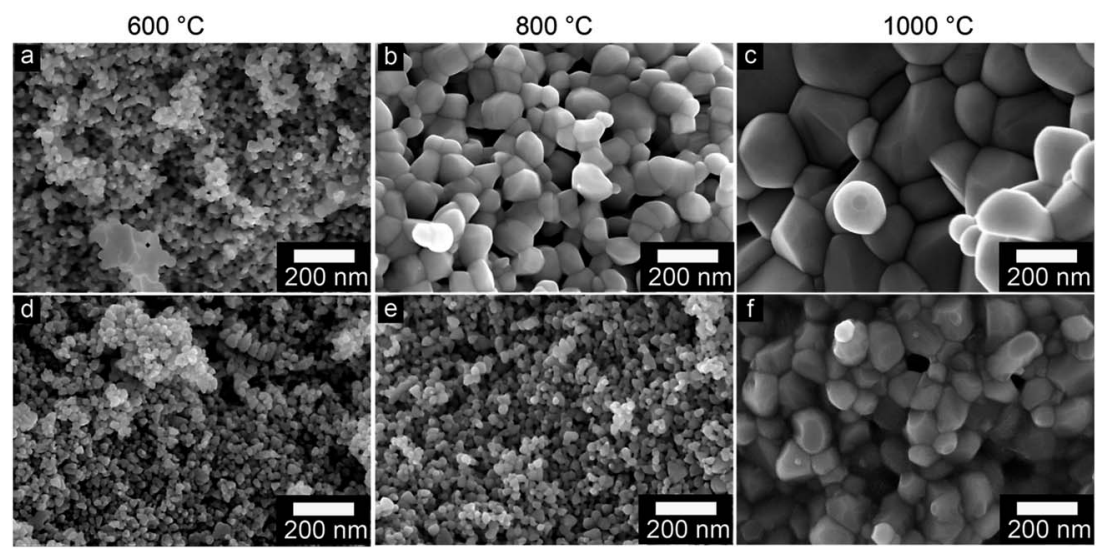

Fig. 8 Scanning electron micrographs of $(\mathrm{a}-\mathrm{c})$ pristine and $(\mathrm{d}-\mathrm{f})$ OTMS-coated ZnO nanoparticles after heat treatment in nitrogen for $1 \mathrm{~h}$ at different temperatures. 

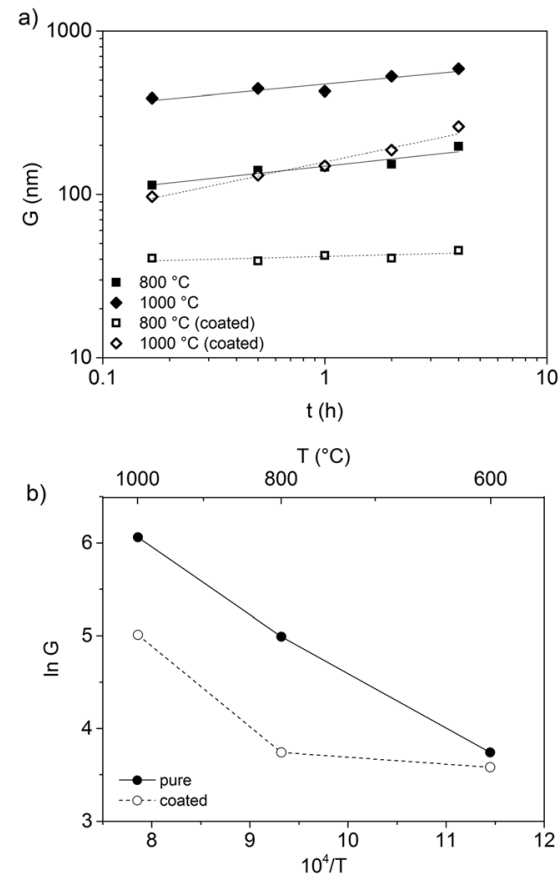

Fig. 9 (a) Isothermal grain growth rate (log scale) plotted as a function of time (log scale) for ZA-8g nanoparticles with and without coating. Ambient medium: nitrogen. (b) Arrhenius plot of the grain growth rate for coated and uncoated ZA-8g nanoparticles.

Table 2 Activation energies and kinetic grain growth exponents of $\mathrm{ZnO}$ nanoparticles with and without OTMS coating during heat treatment in nitrogen ${ }^{a}$

\begin{tabular}{lrrll}
\hline Sample & $n_{\mathrm{LT}}$ & $n_{\mathrm{HT}}$ & $\begin{array}{l}Q_{\mathrm{LT}} \\
\left.(\mathrm{kJ} \mathrm{mol})^{-1}\right)\end{array}$ & $\begin{array}{l}Q_{\mathrm{HT}} \\
\left(\mathrm{kJ} \mathrm{mol}^{-1}\right)\end{array}$ \\
\hline ZA-8g (pristine) & 7.8 & 6.8 & 332 & 253 \\
ZA-8g (coated) & 28.9 & 3.5 & 180 & 475
\end{tabular}

${ }^{a}$ LT and HT were used for temperatures below and above $800{ }^{\circ} \mathrm{C}$, respectively.

is $1 / n$. The slope of the fitted line of $\ln G v s . T^{-1}$ gives the activation energy (Fig. 9b, Table 2). The high activation energies of pristine $\mathrm{ZnO}$ nanoparticles suggested that the volume diffusion was the rate-controlling mechanism. However, the low activation energy obtained with the OTMS surface coating on the $\mathrm{ZnO}$ particles indicated that surface diffusion was the dominating sintering mechanism at temperatures below $800{ }^{\circ} \mathrm{C}$. At $1000{ }^{\circ} \mathrm{C}$, the surface diffusion changed to volume diffusion, resulting in larger grains at higher temperatures. It was concluded that silane coating is an effective way for impeding the grain growth during heat treatment and the removal of surface defects.

Heat treatment transformed the silane coating to silica while the zinc hydroxy salt defects decomposed, yielding pure ZnO. It was necessary to remove the silica layer in order to produce nano-sized $\mathrm{ZnO}$ with an active hydroxylated surface. The presence of the hydroxyl groups on $\mathrm{ZnO}$ surfaces is of paramount importance due to their pronounced effect on the chemical activity of the nanoparticles in nanocomposites. ${ }^{52}$ XPS was used to characterize the surface composition. Fig. 10a-c show the high resolution spectra of the $\mathrm{C} 1 \mathrm{~s}, \mathrm{Si} 2 \mathrm{p}$ and $\mathrm{O} 1 \mathrm{~s}$ photoelectrons for the synthesized nanoparticles (ZA-8g), the silica-coated nanoparticles after heat treatment at $600{ }^{\circ} \mathrm{C}(\mathrm{TS})$ and the sample etched with $\mathrm{NaOH}$ solution (TS-E). The $\mathrm{C} 1 \mathrm{~s}$ region shows two peaks for the ZA-8g sample at 285.0 and $288.9 \mathrm{eV}$ due to $\mathrm{C}-\mathrm{C}$ and $\mathrm{C}=\mathrm{O}$ bonds $^{75}$ in acetate groups on the $\mathrm{ZnO}$ nanoparticle surfaces in the ZHS phase. ${ }^{76}$ These peaks were absent after coating/heat treatment of the TS sample, indicating that ZHS defects had been removed by the heat treatment. The Si $2 \mathrm{p}$ region shows that the silica peak at $102.4 \mathrm{eV}$ was absent after the etching of $\mathrm{ZnO}$ nanoparticle surfaces with $\mathrm{NaOH}$ solution. The $\mathrm{O} 1 \mathrm{~s}$ region shows one peak at $530.0 \mathrm{eV}$ with a large shoulder at $531.4 \mathrm{eV}$ for the $\mathrm{ZA}-8 \mathrm{~g}$ sample, assigned to $\mathrm{O}^{2-}$ ions in the Wurtzite structure and $\mathrm{OH}$ groups on the synthesized $\mathrm{ZnO}$ nanoparticle surfaces, respectively. The peak assigned to hydroxyl groups disappeared after coating/heat treatment of the TS sample. This peak reappeared after etching the silica shell in the TS-E sample, indicating the hydroxylated surface of the final ZnO nanoparticles. The coating/heat treatment/etching process thus provided the nano-sized $\mathrm{ZnO}$ particles with activated hydroxyl surfaces without the presence of associated ionic species. These ultra-pure $\mathrm{ZnO}$ nanoparticles with the capability of up-scaling have not been reported to the best of our knowledge. These nanoparticles show their high potential in ultra-low electrically conductive nanocomposites where the absence of the ionic/polar species is of paramount importance.
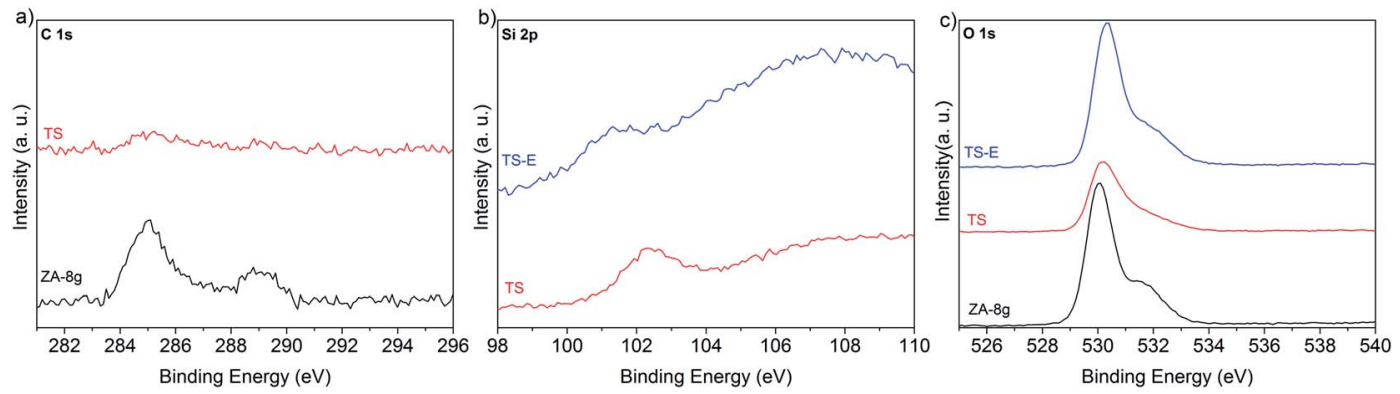

Fig. 10 High resolution XPS spectra of synthesized nanoparticles (ZA-8g), silica-coated nanoparticles after the heat treatment at $600{ }^{\circ} \mathrm{C}(\mathrm{TS})$ and the sample etched with $\mathrm{NaOH}$ solution (TS-E). 


\section{Conclusions}

This study presents two methods using a suitable particle orientation and coating of $\mathrm{ZnO}$ nanoparticles to obtain nanosized and ultra-pure $\mathrm{ZnO}$ grains/particles in a single-step heat treatment at low temperatures. The oriented nanoparticle systems obtained by the initial synthesis were more densely packed than the systems consisting of non-oriented nanoparticles and this led to a reduction in the grain growth during heat treatment. The nano-sized and dense $\mathrm{ZnO}$ ceramics with a high concentration of grain boundaries have a potential use in varistor applications. Another method was based on silane coating of $\mathrm{ZnO}$ nanoparticles which inhibited the sintering during heat treatment. The hydroxylated surface of the $\mathrm{ZnO}$ nanoparticles was recovered by alkaline etching of the silica shell. This process makes possible the synthesis of ultra-pure nanoparticles with a hydroxide functional surface and, most importantly, without the presence of counter-ions. These nanoparticles have potential for use in polyethylene nanocomposites within the insulating layer of extruded HVDC cables.

\section{Acknowledgements}

The Swedish Foundation for Strategic Research (EM11-0022) is acknowledged for providing the financial support for this study.

\section{References}

1 H. Sellerholm, Report 14:21, Elforsk AB, Stockholm, 2014.

2 A. Gustafsson, M. Saltzer, A. Farkas, H. Ghorbani, T. Quist and M. Jeroense, The new $525 \mathrm{kV}$ extruded HVDC cable system, ABB Grid Systems, 2014.

3 F. Tian, Q. Lei, X. Wang and Y. Wang, Appl. Phys. Lett., 2011, 99, 142903.

4 D. Liu, A. M. Pourrahimi, R. T. Olsson, M. S. Hedenqvist and U. W. Gedde, Eur. Polym. J., 2015, 66, 67-77.

5 L. K. H. Pallon, R. T. Olsson, D. Liu, A. M. Pourrahimi, M. S. Hedenqvist, A. T. Hoang, S. Gubanski and U. W. Gedde, J. Mater. Chem. A, 2015, 3, 7523-7534.

6 A. M. Pourrahimi, D. Liu, L. K. H. Pallon, R. L. Andersson, A. Martinez Abad, J. M. Lagaron, M. S. Hedenqvist, V. Strom, U. W. Gedde and R. T. Olsson, RSC Adv., 2014, 4, 35568-35577.

7 A. Degen and M. Kosec, J. Eur. Ceram. Soc., 2000, 20, 667-673. 8 S. Musić, Đ. Dragčević and S. Popović, J. Alloys Compd., 2007, 429, 242-249.

9 S. Liu, E. Killen, M. Lim, C. Gunawan and R. Amal, RSC Adv., 2014, 4, 4363-4370.

10 F. Demoisson, R. Piolet and F. Bernard, Cryst. Growth Des., 2014, 14, 5388-5396.

11 A. Moezzi, A. McDonagh, A. Dowd and M. Cortie, Inorg. Chem., 2012, 52, 95-102.

12 H. Morioka, H. Tagaya, J. I. Kadokawa and K. Chiba, J. Mater. Sci. Lett., 1999, 18, 995-998.

13 A. Moezzi, M. B. Cortie and A. M. McDonagh, Dalton Trans., 2013, 14432-14437.
14 X. Zhao, F. Zhang, S. Xu, D. G. Evans and X. Duan, Chem. Mater., 2010, 22, 3933-3942.

15 D. Segets, R. Marczak, S. Schäfer, C. Paula, J.-F. Gnichwitz, A. Hirsch and W. Peukert, ACS Nano, 2011, 5, 4658-4669.

16 D. Sun, M. Wong, L. Sun, Y. Li, N. Miyatake and H.-J. Sue, J. Sol-Gel Sci. Technol., 2007, 43, 237-243.

17 Y. Piao, J. Kim, H. B. Na, D. Kim, J. S. Baek, M. K. Ko, J. H. Lee, M. Shokouhimehr and T. Hyeon, Nat. Mater., 2008, 7, 242-247.

18 J. I. Hong, L. S. Schadler, R. W. Siegel and E. Mårtensson, Appl. Phys. Lett., 2003, 82, 1956-1958.

19 N. Neves, R. Barros, E. Antunes, I. Ferreira, J. Calado, E. Fortunato and R. Martins, J. Am. Ceram. Soc., 2012, 95, 204-210.

20 T. K. Gupta, J. Am. Ceram. Soc., 1990, 73, 1817-1840.

21 M. Maleki Shahraki, S. Ali Shojaee, M. A. Faghihi Sani, A. Nemati and I. Safaee, Solid State Ionics, 2011, 190, 99-105. 22 M. Michio, Jpn. J. Appl. Phys., 1971, 10, 736.

23 M. Takata, D. Tsubone and H. Yanagida, J. Am. Ceram. Soc., 1976, 59, 4-8.

24 M. Chaari, Mater. Sci. Appl., 2011, 765-770.

25 X. Li, L. Xu, L. Liu, Y. Wang, X. Cao, Y. Huang, C. Meng and Z. Wang, J. Mater. Chem. A, 2014, 2, 16740-16745.

26 S. C. Pillai, J. M. Kelly, R. Ramesh and D. E. McCormack, J. Mater. Chem. C, 2013, 1, 3268-3281.

27 L. Meng, L. Zheng, L. Cheng, G. Li, L. Huang, Y. Gu and F. Zhang, J. Mater. Chem., 2011, 21, 11418-11423.

28 D. Nina, B. Slavko and R. Aleksander, J. Phys.: Conf. Ser., 2011, 326, 012003.

29 E. Suvaci and İ. Ö. Özer, J. Eur. Ceram. Soc., 2005, 25, 16631673.

30 P. Durán, F. Capel, J. Tartaj and C. Moure, Adv. Mater., 2002, 14, 137-141.

31 D. Dollimore and P. Spooner, Trans. Faraday Soc., 1971, 67, 2750-2759.

32 S.-D. Shin, C.-S. Sone, J.-H. Han and D.-Y. Kim, J. Am. Ceram. Soc., 1996, 79, 565-567.

33 D. E. Wurster, E. Oh and J. C. T. Wang, J. Pharm. Sci., 1995, 84, 1301-1307.

34 I. W. Chen and X. H. Wang, Nature, 2000, 404, 168-171.

35 B. Chen, Z. Xia and K. Lu, J. Eur. Ceram. Soc., 2013, 33, 24992507.

36 M. Mazaheri, A. M. Zahedi and S. K. Sadrnezhaad, J. Am. Ceram. Soc., 2008, 91, 56-63.

37 R. Roy, D. Agrawal, J. Cheng and S. Gedevanishvili, Nature, 1999, 399, 668-670.

38 T. Hungría, J. Galy and A. Castro, Adv. Eng. Mater., 2009, 11, 615-631.

39 T. Senda and R. C. Bradt, J. Am. Ceram. Soc., 1990, 73, 106114.

40 J. Han, P. Q. Mantas and A. M. R. Senos, J. Eur. Ceram. Soc., 2000, 20, 2753-2758.

41 M. Mazaheri, S. A. Hassanzadeh-Tabrizi and S. K. Sadrnezhaad, Ceram. Int., 2009, 35, 991-995.

42 A. P. Hynes, R. H. Doremus and R. W. Siegel, J. Am. Ceram. Soc., 2002, 85, 1979-1987. 
43 A. P. A. Oliveira, J.-F. Hochepied, F. Grillon and M.-H. Berger, Chem. Mater., 2003, 15, 3202-3207.

44 Z. Zhang, H. Sun, X. Shao, D. Li, H. Yu and M. Han, Adv. Mater., 2005, 17, 42-47.

45 J. Mouzon, M. Odén, O. Tillement and Y. Jorand, J. Am. Ceram. Soc., 2006, 89, 3094-3100.

46 X. Gu, S. Sabuktagin, A. Teke, D. Johnstone, H. Morkoç, B. Nemeth and J. Nause, J. Mater. Sci.: Mater. Electron., 2004, 15, 373-378.

47 D. V. Wagle and G. A. Baker, Mater. Horiz., 2015, 2, 157-167.

48 P. Uthirakumar, B. Karunagaran, S. Nagarajan, E.-K. Suh and C.-H. Hong, J. Cryst. Growth, 2007, 304, 150-157.

49 Y. Wang, Y. Li, Z. Zhou, X. Zu and Y. Deng, J. Nanopart. Res., 2011, 13, 5193-5202.

50 G. R. Williams, J. Crowder, J. C. Burley and A. M. Fogg, J. Mater. Chem., 2012, 22, 13600-13611.

51 H. Staroszczyk and P. Janas, Carbohydr. Polym., 2010, 80, 962-969.

52 H. Noei, H. Qiu, Y. Wang, E. Loffler, C. Woll and M. Muhler, Phys. Chem. Chem. Phys., 2008, 10, 7092-7097.

53 H. Wang and C. Xie, J. Phys. Chem. Solids, 2008, 69, 24402444.

54 S. J. Gregg and K. S. W. Sing, Adsorption, surface area, and porosity, Academic Press, 1991.

55 K. Kaneko, J. Membr. Sci., 1994, 96, 59-89.

56 M.-Y. Chu, M. N. Rahaman, L. C. de Jonghe and R. J. Brook, J. Am. Ceram. Soc., 1991, 74, 1217-1225.

57 L. C. De Jonghe, M.-Y. Chu and M. F. Lin, J. Mater. Sci., 1989, 24, 4403-4408.

58 F. Wakai, Y. Shinoda and T. Akatsu, Acta Mater., 2004, 52, 5621-5631.
59 C. Suryanarayana and M. G. Norton, X-ray diffraction: $a$ practical approach, Springer, 1998.

60 H. Zeng, G. Duan, Y. Li, S. Yang, X. Xu and W. Cai, Adv. Funct. Mater., 2010, 20, 561-572.

61 A. K. Zak, M. E. Abrishami, W. Majid, R. Yousefi and S. Hosseini, Ceram. Int., 2011, 37, 393-398.

62 S. Vempati, J. Mitra and P. Dawson, Nanoscale Res. Lett., 2012, 7, 1-10.

63 Z. Chen, N. Zhang and Y.-J. Xu, CrystEngComm, 2013, 15, 3022-3030.

64 Y. H. Leung, Z. B. He, L. B. Luo, C. H. A. Tsang, N. B. Wong, W. J. Zhang and S. T. Lee, Appl. Phys. Lett., 2010, 96, 053102.

65 M. Yang, K. Sun and N. A. Kotov, J. Am. Chem. Soc., 2010, 132, 1860-1872.

66 X. Pan, M.-Q. Yang and Y.-J. Xu, Phys. Chem. Chem. Phys., 2014, 16, 5589-5599.

67 X. Liu and M. T. Swihart, Nanoscale, 2013, 5, 8029-8036.

68 L. Vayssieres, K. Keis, A. Hagfeldt and S.-E. Lindquist, Chem. Mater., 2001, 13, 4395-4398.

69 J. Wu, T. Li, C. Wang, B. Zhu, R. Wu and C. Xie, Ceram. Int., 2011, 37, 3469-3476.

70 X. J. Qin, G. J. Shao, R. P. Liu and W. K. Wang, J. Mater. Sci., 2005, 40, 4943-4946.

71 J. Wong, J. Appl. Phys., 1980, 51, 4453-4459.

72 T. K. Gupta and R. L. Coble, J. Am. Ceram. Soc., 1968, 51, 521525.

73 G. C. Nicholson, J. Am. Ceram. Soc., 1965, 48, 214-215.

74 M. I. Mendelson, J. Am. Ceram. Soc., 1969, 52, 443-446.

75 B. Weng, M.-Q. Yang, N. Zhang and Y.-J. Xu, J. Mater. Chem. A, 2014, 2, 9380-9389.

76 S.-W. Bian, I. A. Mudunkotuwa, T. Rupasinghe and V. H. Grassian, Langmuir, 2011, 27, 6059-6068. 